\title{
EFFECT OF FREE ELECTRONS IN STEEL ON ITS QUENCHING PROCESS IN WATER AND WATER SALT SOLUTIONS
}

\author{
Nikolai Kobasko \\ Intensive Technologies Ltd \\ 68/1 Peremohy ave., Kyiv, Ukraine, 03113 \\ nkobasko@gmail.com
}

\begin{abstract}
In the paper some phenomena of physics taking place during quenching steel in liquid media are widely discussed. It is shown that a double electrical layer is responsible for unknown impulse like effect constantly observed during quenching probes in electrolytes. It can be used for transient nucleate boiling process evaluation that is a basis for designing intensive quenching technology known as IQ-2 process. Early published phenomena of physics such as a poker effect, two stage cooling, and optimal concentration of electrolytes have the common nature - free electrons in metal. The observed phenomena of physics can be governed by hyperbolic heat conductivity equation with the appropriate initial and boundary conditions instead of parabolic heat conductivity widely used equation. At present time, fortunately, mathematicians started seriously investigations in this area by solving hyperbolic heat conductivity equations which can release in the future more new unknown phenomena to be widely used in the practice.
\end{abstract} technology.

Keywords: phenomena, poker effect, double electrical layer, optimal concentration, two stages, emitters, resonance, new

\section{Introduction}

The paper discusses physical processes taking place during quenching steel in liquid media such as film and nucleates boiling modes, behavior of free electrons in metal during quenching, double electrical layer, thermal waves, and others [1-3]. During hardening steel parts from high temperatures $\left(800-900{ }^{\circ} \mathrm{C}\right.$ ) in liquid media three stages of heat transfer occur (Fig. 1, a). These stages reflect three different cooling mechanisms that occur during the quenching of hot metals. These three cooling zones are known as stages A, B, and C [1]. Stage A, or the vapor blanket stage, is characterized by a stable film boiling around the hot metal. Upon further cooling, stage B, or transient nucleate boiling stage begins. This cooling mechanism is characterized by violent boiling at the metal surface. Stage C, or convective cooling stage, begins when the metal cools below the boiling point of the quenching fluid [1]. Based on modified law of Fourier and hyperbolic heat conductivity equation, the paper discusses some physical phenomena taking place during quenching steel parts and probes in water salt (alkali) solutions known as electrolytes. The aim of the paper is considering hardening processes from the point of view of physics to make existing intensive quenching (IQ) processes more effective and inexpensive.

\section{Two stages of cooling during quenching in liquid media instead of three ones}

Engineers and scientists believe that during quenching from austenitizing temperature $\left(800-900^{\circ} \mathrm{C}\right.$ ) in liquid media always must take place three stages A, B and C. The first is relayed on the everyday practice and parabolic heat conductivity equation, according to which initial heat flux density during quenching tends to infinity. If so, initial heat flux density always exceeds the first critical heat flux density of any liquid that is why always shorter or longer film boiling exists. Many prominent scientists supported this idea. However, painstaking experiments of French made in 1928-1930 showed that film boiling during quenching from $875{ }^{\circ} \mathrm{C}$ in slightly agitated $5 \%$ alkali water solution at $20{ }^{\circ} \mathrm{C}$ is completely absent (Fig. 1, b and Table 1) [4]. 

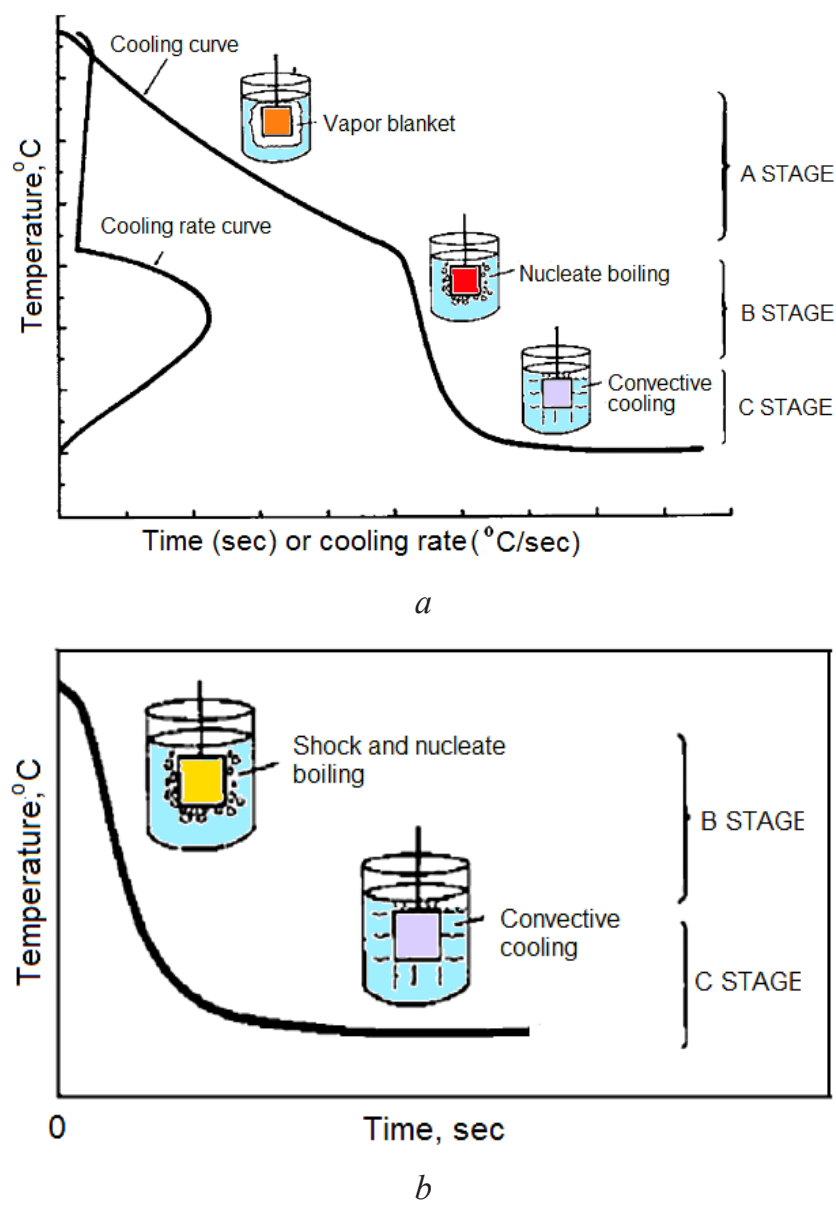

Fig. 1. Possible three and two stages of cooling observed during hardening of steel parts in liquid media: $a$ shows three stages of cooling; $b$ shows two stages of cooling; A is vapor blanket stage or developed full film boiling; $\mathrm{B}$ is transient nucleate boiling stage; $\mathrm{C}$ is convective cooling stage $[1,2]$

\section{Table 1}

Cooling time of different steel components and probes needed for reducing surface temperature from $875^{\circ} \mathrm{C}$ to $150{ }^{\circ} \mathrm{C}$ when hardening in liquid media

\begin{tabular}{|c|c|c|c|c|c|}
\hline Steel component & Diameter in mm & Method of quenching & Cooling time in sec & Year & Authors \\
\hline \multirow{5}{*}{ Steel spheres } & 6.35 & \multirow{5}{*}{$\begin{array}{l}\text { Quenching in } 5 \% \mathrm{NaOH} \\
\text { water solution at } 20^{\circ} \mathrm{C} \\
\text { moving with } 0.9 \mathrm{~m} / \mathrm{s}\end{array}$} & 0.59 & 1930 & {$[4]$} \\
\hline & 12.7 & & 0.60 & 1930 & {$[4]$} \\
\hline & 25.4 & & 0.82 & 1930 & {$[4]$} \\
\hline & 63.5 & & 0.59 & 1930 & {$[4]$} \\
\hline & 180 & & 1.15 & 1930 & {$[4]$} \\
\hline Truck semi-axles & 52 & $\begin{array}{l}\text { Quenching in water flow } \\
\qquad 8 \mathrm{~m} / \mathrm{s} \text { at } 20^{\circ} \mathrm{C}\end{array}$ & 0.1 & 1967 & {$[5]$} \\
\hline Steel cylindrical probe & 28 & $\begin{array}{l}\text { Quenching in water flow } \\
1.5 \mathrm{~m} / \mathrm{s} \text { at } 20^{\circ} \mathrm{C}\end{array}$ & 1.5 & 2012 & {$[6]$} \\
\hline Steel cylindrical probe & 50.8 & $\begin{array}{l}\text { Quenching in water flow } \\
\qquad 4 \mathrm{~m} / \mathrm{s} \text { at } 20^{\circ} \mathrm{C}\end{array}$ & $<2$ & 2013 & {$[7]$} \\
\hline Cylindrical steel probes & $6,12,20,30,50$ & $\mathrm{CaCl}_{2}$ water solutions & $<1$ & 1980 & {$[8]$} \\
\hline
\end{tabular}


As seen from Table 1, surface temperature drops from $875^{\circ} \mathrm{C}$ to $150{ }^{\circ} \mathrm{C}$ almost instantly, so there is no time left for the transient film boiling development. It is rather strange because initial temperature and heat flux density were very high. Some additional forces between steel part and quenchant should be present to prevent development of film boiling. Frenkel [2] developed a theory on formation a double electrical layer between liquid and metallic surface which creates mentioned above additional forces. Using theory of Frenkel, author [8, 9] came to conclusion that, due to double electrical layer, an optimal concentration of salt (alkali) water solution should exist which provides maximal critical heat flux densities. When using salt solution of optimal concentration as a quenchant, probability of film boiling formation is minimal because increased critical heat flux density. To solve this problem completely, one should consider hyperbolic heat conductivity equation instead of parabolic equation.

As known, conventional heat conductivity law of Fourier (1)

$$
q=-\lambda \frac{\partial T}{\partial r}
$$

combined with the conservation law of energy, generates parabolic heat conductivity equation (2)

$$
\frac{\partial \mathrm{T}}{\partial \tau}=\operatorname{adiv}(\operatorname{grad} \mathrm{T})
$$

And modified heat conductivity law of Fourier (3)

$$
q=-\lambda \frac{\partial T}{\partial r}-\tau_{r} \frac{\partial T}{\partial \tau}
$$

generates hyperbolic heat conductivity equation (4) [10]:

$$
\frac{\partial \mathrm{T}}{\partial \tau}+\tau_{\mathrm{r}} \frac{\partial^{2} \mathrm{~T}}{\partial \tau^{2}}=\operatorname{adiv}(\operatorname{grad} \mathrm{T}) .
$$

The first says that the speed of heat and initial heat flux density during quenching are infinity, the second says that both are finite values [10]. If so, theoretically initial heat flux can be lesser than critical one and that means absence of film boiling at all (Fig. 1, b). Modified law of Fourier and hyperbolic heat conductivity equation take into consideration free electrons in metal and, due to this fact, it was possible to explain "poker effect" when hands of worker keeping cold end of poker can be burned during water cooling of hot end of a poker [3]. According to hyperbolic heat conductivity equation, the thermal wave is mowing from hot to cold end of a poker, presented as

$$
\theta(x, \tau)=\frac{\sqrt{\tau_{r}}}{\sqrt{\tau}} e^{-\frac{x^{2}}{4 a \tau}}
$$

with a speed $\mathrm{w}_{\mathrm{r}}$

$$
\mathrm{w}_{\mathrm{r}}=\sqrt{\frac{\mathrm{a}}{\tau_{\mathrm{r}}}} .
$$

Here $\mathrm{T}$ is temperature; $\tau$ is time; $\mathrm{q}$ is heat flux density; $\lambda$ is thermal conductivity of steel; a is thermal diffusivity of steel; $\tau_{\mathrm{r}}$ is a value which is called relaxation time and is characteristic of a free electrons movement in metal and is constant which depends on the nature of a material. $\mathrm{x}$ and $\mathrm{r}$ are coordinate; $\theta$ is dimensionless temperature. 
Authors [3] were the first who scientifically explained correctly the interesting poker effect taking into account free electrons in metal and considering hyperbolic heat conductivity equation for two stages of cooling. Further very important 3-D direct and inverse solutions of hyperbolic heat conductivity equation with the appropriate boundary and initial conditions were received by mathematicians [11-15]. It would be a great work done if mathematicians could explain physical meaning of their solutions presenting more practical graphs and tables to be used in practice by engineers.

\section{A double electrical layer}

The main question of establishing a double electrical layer is knowledge the nature of metal surface charge. Is it positive or negative? At the beginning, authors [16] accepted model which considered metal surface charged positively (Fig. 2, a). Authors [16] believed that heated to high temperature metal loses its free electrons that during immersion into liquid results in negative charge of liquid boundary layer.

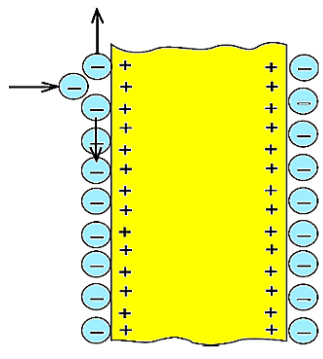

$a$

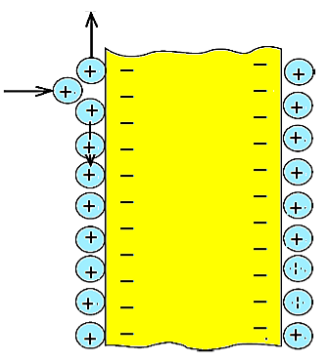

b

Fig. 2. A double electrical layer: $a$-old model; $b$ - new model

However, further consideration of the laws of statistical physics changed the belief of authors $[17,18]$. According to statistical physics, free electrons are moving from heated area to cold area creating a negative charge on the metal surface (Fig. 2, b). Moreover, if metal surface during cooling is charged positively, it will be impossible to explain the nature of poker effect because then no thermal wave can exist at all. Also, this issue is very important for chemistry because knowing the nature of the double electrical layer one can prepare optimized solution used as a quenchant. Some investigations in this field were started in 1977 which allowed evaluating optimal concentration for many water salt solutions (Fig. 3) $[8,9]$.

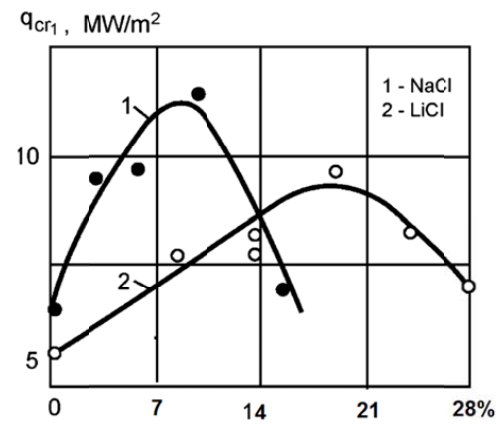

Fig. 3. Maximal critical heat flux densities $\mathrm{q}_{\mathrm{crl}}$ versus concentration for $\mathrm{NaCl}$ and $\mathrm{LiCl}$ [17]: 1 is $\mathrm{NaCl} ; 2$ is $\mathrm{LiCl}$.

As seen from Fig. 3, optimal concentration increases extensively the first critical heat flux $\mathrm{q}_{\mathrm{crl}}$ that in many cases eliminates film boiling processes completely. Such critical heat flux densities should be evaluated for solutions widely used in practice as a quenchant. Along with critical heat flux densities, real and effective heat transfer coefficients should be evaluated for different heat transfer modes: film boiling, nucleate boiling and convection. More attention should be paid to 
local and full film boiling processes during quenching measuring their frequency of oscillations to have possibility to eliminate them by resonance effect [17]. In this consideration, recently published results [19] can be used to investigate local film boiling processes.

\section{A strange effect observed during quenching standard probes in electrolytes}

A quenchant, based on use optimal water salt solutions of $\mathrm{CaCl}_{2}$ or $\mathrm{MgCl}_{2}$ with additives of $\mathrm{Ca}(\mathrm{OH})_{2}$ to keep $\mathrm{pH}$ of water salt solutions at the level of 8-12, was used in Ukraine within 19831999. During testing of water salt solution of $\mathrm{CaCl}_{2}$, a strange effect was noticed by investigators on the cooling rate curve. The second maximum was constantly observed on cooling rate curve. At the beginning, investigators thought that it was caused by incorrectly instrumentation of thermocouple. To make ideal contact junction of thermocouple with a steel probe a special instrumentation was used as shown in Fig. 4 which was quenched in water $\mathrm{CaCl} 2$ solutions of different concentration.

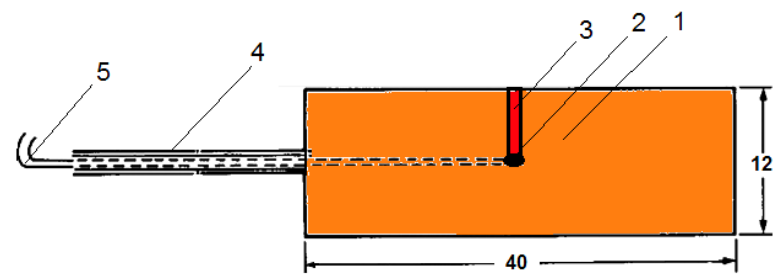

Fig. 4. A probe made of AISI 304 steel for obtaining accurate data on core cooling curves and core cooling rate curves: 1 is probe; 2 is thermocouple; 3 is a pin to press velded thermocouple;

4 is tube; 5 are xromel and alumel wires

First, junction of thermocouple was welded and then fixed thoroughly by a pin as shown in Fig. 4. In spite of these accurate preparations, the second maximum on cooling rate curve didn't disappear at all, but became more sharply seen (Fig. 5, a-d). Nobody could explain such strange behavior of thermocouple. Authors $[20,21]$ who observed similar effect during quenching in water solutions of $\mathrm{Na}_{2} \mathrm{CO}_{3}$ published several papers without paying attention to this effect and its explanation. Let's consider more attentively results of accurate experiments shown in Fig. $\mathbf{5}$ which were received during quenching of probe $40 \mathrm{~mm}$ in diameter in water $\mathrm{CaCl}_{2}$ solutions of different concentration.

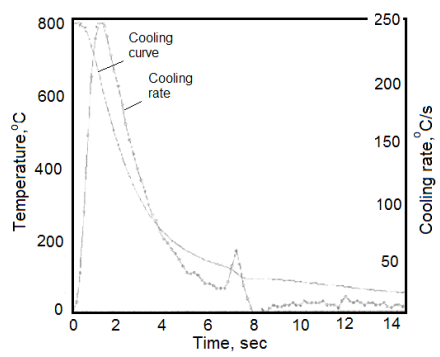

$a$

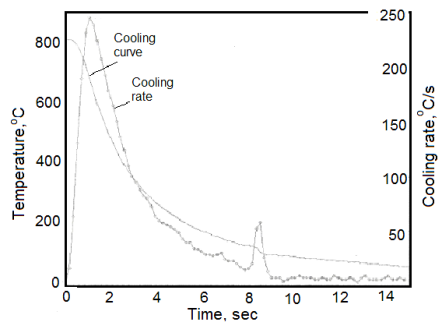

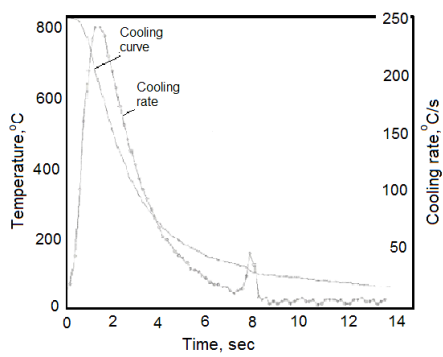

$b$

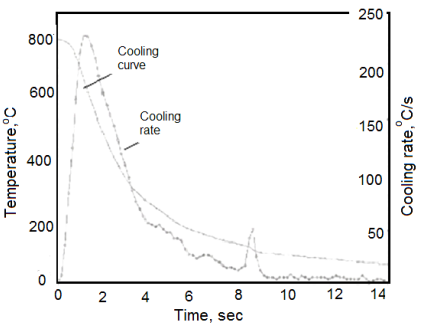

d

Fig. 5. Cooling temperature curves and cooling rate curves vs. time when quenching $40 \mathrm{~mm}$ probe made of AISI 304 steel in water salt solutions of $\mathrm{CaC}_{2}$ at $20{ }^{\circ} \mathrm{C}$ : $a$ is $8 \% ; b$ is $10 \%$; $c$ is $12 \% ; d$ is $14 \%$ solution 
As seen from Fig. 5, the second maximum of cooling rate was observed in all experiments.

Table 2

Time of the second maximum cooling rate versus water concentration of $\mathrm{CaCl}_{2}$

\begin{tabular}{cccc}
\hline Concentration, $\%$ & To & Max cooling rate & Time of second max, sec \\
\hline 8 & 799 & 249 & 6.7 \\
10 & 798 & 239 & 7.3 \\
12 & 814 & 246 & 7.8 \\
14 & 806 & 228 & 8.3
\end{tabular}

Table 2 provides the time of second maximum formation on cooling rate curve. It can be explained by destroying the double electrical layer in convection area due to low temperature gradient through the section of the probe.

5. Modified IQ-2 technology based on resonance effect produced by hydrodynamics emitters

During batch quenching within the load local film boiling processes take place resulting in non-smooth cooling, non-uniform surface hardness and big distortion of steel parts after quenching. To prevent such unpleasant effects, engineers use vigerous agitation of liquid quenchant produced by propellers in tanks. However, if steel parts in load are tightly arrenged, water flow restriction is observed inside the load and agitation of liquid cannot eliminate completely local film boiling. To solve this problem, the resonance effect was explored for batch quenching processes [17]. Its essense is as follows. Any local film boiling produces waves with surtain frequences which can be measured by special system. Knowing frequences of local film boiling processes, one can use emitters developing waves the same frequencves as local film boiling do to establish resonance effect inside the load. As known, there is no essential restriction for wave distribution inside the load. Due to resonace effect, any film boiling inside the load is absent. A scheme of emitters arragment in quench tank is shown in Fig. 6.

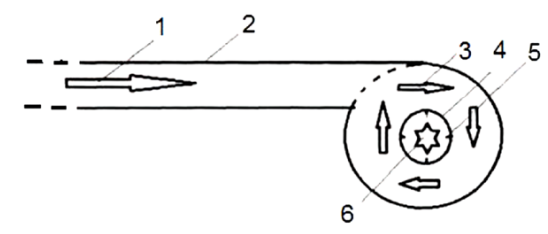

$a$

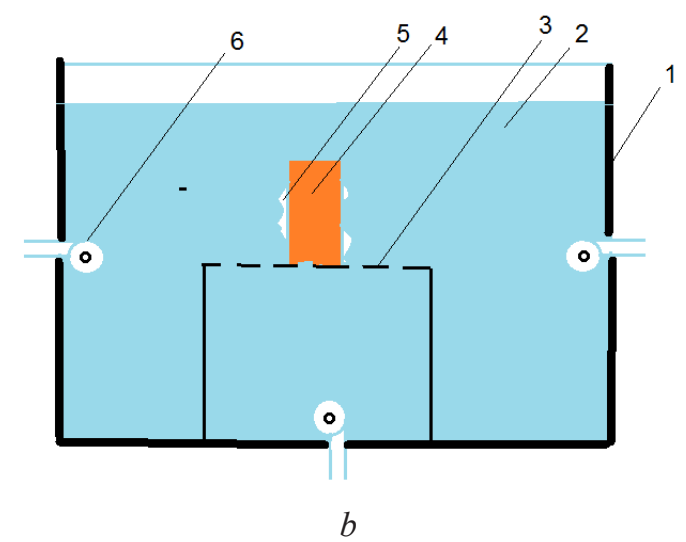

Fig. 6. Emitter and its arrangement in quench tank: $a$ is emitter, where 1 is liquid flow, 2 is tube, 3 is circulated liquid stream, 4 is generator waves in liquid, 5 is regulator of wave frequency, 6 is liquid flow combined with generated waves; $b$ is quench tank with located in it emitters, where 1 is quench tank; 2 is water salt solution of optimal concentration; 3 is fixture;

4 is steel part; 5 is local film boiling; 6 is emitter. 
Along with the resonance effect, the optimal concentration of water salt solution is used which provides maximal critical heat flux densities. Combining optimal concentration of water salt solutions with resonance effect allows elimination of film boiling processes. More information on existing quenching technologies, including intensive quenching processes, one can find in [22-24].

\section{Discussion}

As seen from all presented above, there is a lot of work to do for many specialists to optimize quenching processes in liquid media. Especially, initial quenching process is not yet investigated deeply and widely where some phenomena of physics are observed. Probably, further investigations in this field should be organized by International Federation for Heat Treating and Surface Engineering (IFHTSE) which already started developing liquid quenchant DATABASE to be used by engineers for computer simulation and new technologies designing [25, 26]. Especially, a serious attention should be paid to critical heat flux densities, real and effective heat transfer coefficients to be investigated by properly designed probes and measuring system like sonar system, video observation, and accurate temperature field measurement. Currently, investigations in this field are carried out by many institutions and there is no strongly developed strategy what to do and how to do. As a result, many big companies are not using $100 \%$ benefits from contemporary technologies.

\section{Conclusions}

1. During immersion of heated metal into cold electrolytes some new phenomena of physics are observed and cooling process is governed in this case by hyperbolic heat conductivity equation with the appropriate initial and boundary conditions. Poker effect follows from the solution of hyperbolic heat conductivity equation.

2. Nature of observed phenomena of physics such as a double electrical layer, poker effect, impulse like effect, two stage quenching process is the same - free electrons in metal. As a result, surface of metal must be charged negatively, not positively.

3. The impulse like effect presented by second maximum of probe cooling rate is not investigated properly yet and it can be used in the future in studying transient nucleate boiling processes that make a basis for IQ-2 technology. It is explained by destroying a double electrical layer.

4. The aim of this paper is study of the physics of quenching heated steel in liquid media to reduce radically cost of current hardening technologies by applying resonance effect to possible local and full film boiling modes that eliminates these modes very effectively. Waves produced by emitter don't face essential hydrodynamic restriction inside the load that makes sense to use them.

\section{References}

[1] Totten, G. E., Bates, C. E., Clinton, M. A. (1993). Handbook of Quenchants and Quenching Technology. Materials Park, Ohio: ASM International, 507.

[2] Frenkel, Ya. I. (1975). Kinetic Theory of Liquids. Leningrad: Nauka, 570.

[3] Kobasko, N. I., Guseynov, Sh. E.; Bolas, V. E., Koksal, M. (Eds.) (2012). An Explanation of the Nature of Thermal Waves «a Poker Effect» on the Basis of Hyperbolic Heat Conductivity Equation Analysis and Existence of Free Electrons in Metal. Resent Researches in Circuits \& Systems. Athens: WSEAS Press, 167-172.

[4] French, H. J. (1930). The Quenching of Steels. Cleveland, Ohio, USA: American Society for Steel Treating, 177.

[5] Bogatyrev, Yu. M., Shepelyakovskii, K. Z., Shklyarov, I. N. (1967). Cooling rate effect on crack formation at steel quenching. MiTOM, 11, 15-22.

[6] Kobasko, N. I., Aronov, M. A., Ichitani, K., Hasegawa, M., Noguchi, K.; Jha, M. K., Lazard, M., Zaharim, A., Sopian, K. (Eds.) (2012). High compressive residual stresses in through hardened steel parts as a function of Biot number. Resent Advances in Fluid Mechanics, Heat and Mass Tramsfer and Biology. Athens: WSEAS Press, 35-40.

[7] Powell, J. A. (2013, April 24). Basics of IQ Process, Intensive Quenching Workshop. Cleveland, Ohio, 48 slides.

[8] Kobasko, N. I. (1980). Steel Quenching in Liquid Media under Pressure. Kyiv:Naukova Dumka, 206. 
[9] Fedorov, V. I., Kovalenko, G. V., Kostanchuk, D. M. (1977). Boiling of fluid on a metal surface. Journal of Engineering Physics, 32 (1), 10-14. doi: 10.1007/bf00860120

[10] Lykov, A. V. (1967). Teoriya Teploprovodnosti [Theory of Heat Conductivity]. Moscow: Vysshaya Shkola, 596.

[11] Buike, M., Buikis, A. (2010). Several Intensive Steel Quenching Models for Rectangular Samples. Proceedings of NAUN/WSEAS International Conference on Fluid Mechanics and Heat \&Mass Transfer, Corfu Island, Greece, July 22-24, 2010, 88-93.

[12] Bobinska, T., Buike, M., Buikis, A. (2010). Hyperbolic Heat Equation as Mathematical Model for Steel Quenching of L-and T-Shape Samples, Direct and Inverse Problems. Transactions of Heat and Mass Transfer, 5 (3), 63-72.

[13] Buikis, A., Kalis, H. (2010). Hyperbolic Heat Equation in Bar and Finite Difference chemes of Exact Spectrum. Latest Trends on Theoretical and Applied Mechanics, Fluid Mechanics and Heat \& Mass Transfer. WSEAS Press, 142-147.

[14] Buike, M., Buikis, A., Kalis, H. (2015). Time Direct and Time Inverse Problems for Wave Energy and Steel Quenching Models, Solved Exactly and Approximately. WSEAS Transactions on Heat and Mass Transfer, 10, 30-43.

[15] Buikis, A., Kalis, H. (2015). Hyperbolic type approximation for the solutions of the hyperbolic heat conduction equation in 3-D domain. Mathematical and Computational Methods in Applied Sciences. Proceedings of the 3rd International Conference on Applied, Numerical and Computational Mathematics (ICANCM'15), Sliema, Malta, August 17-19, 2015, 42-51.

[16] Kobasko, N., Aronov, M., Powell, J., Totten, G. (2010). Intensive Quenching Systems: Engineering and Design. ASTM International, 242. doi: 10.1520/mnl64-eb

[17] Kobasko, N. I. (10.09.2015). Intensive Hardening Method for Metal Components. Patent No. UA 109572 C2, MPK: C21D 1/63(2006.01), C21D 1/56 (2006.01), C21D 1/78 (2006.01), C21D 1/18 (2006.01). Filed: 07.10.2013. Bull. No. 17.

[18] Buikis, A., Buike, M. (2017). Intensive wave power and steel quenching 3-D model for cylindrical sample. Time direct and reverse formulations and solutions. ITM Web of Conferences, 9, 01003. doi: 10.1051/itmconf/20170901003

[19] Tensi, H. M., Totten, G. E., Stich, A. (2002). Temperature Measurement Accuracy in Cooling Curve Analysis. Heat Treat Progress, 2 (4), 45-49.

[20] Kobasko, N. I., Moskalenko, A. A., Dobryvechir, V. V., Protsenko, L. M., Dean, S. W. (2012). Intensive Quenching of Steel Parts and Tools in Water Salt Solutions of Optimal Concentration. Journal of ASTM International, 9 (2), 104072. doi: 10.1520/jai104072

[21] Kobasko, N. I., Moskalenko, A. A., Mazurenko, E. A., Medvedev, A. M., (2010). Intensive quenching of tools in water salt solutions. New Aspects of Fluid Mechanics, Heat Transfer and Environment. Athens: WSEAS Press, 320-325.

[22] Liscic, B., Tensi, H. M., Luty, W. (Eds.). (1992). Theory and Technology of Quenching. Berlin, Heidelberg: Springer, 484. doi: 10.1007/978-3-662-01596-4

[23] Liscic, B., Tensi, H., Canale, L., Totten, G. (Eds.). (2010). Quenching Theory and Technology, Second Edition. CRC Press, 725. doi: 10.1201/9781420009163

[24] Dossett, J. I., Totten, G. E. (Eds.) (2013). ASM Handbook, Volume 4A: Steel Heat Treating Fundamentals and Processes. ASM International, 784.

[25] Felde, I. (2016). Liquid quenchant database: determination of heat transfer coefficient during quenching. International Journal of Microstructure and Materials Properties, 11 (3/4), 277. doi: 10.1504/ijmmp.2016.079154

[26] Liscic, B. (2016). Measurement and Recording of Quenching Intensity in Workshop Conditions Based on Temperature Gradients. Materials Performance and Characterization, 5 (1), 209-226. doi: 10.1520/ mpc20160007 